\title{
Identification of biomarkers for intake of protein from meat, dairy products and grains: a controlled dietary intervention study
}

\author{
Wieke Altorf-van der Kuil ${ }^{1,2,3 *}$, Elizabeth J. Brink ${ }^{1}$, Martine Boetje ${ }^{1,2}$, Els Siebelink ${ }^{2}$, Sabina Bijlsma ${ }^{3}$, \\ Marielle F. Engberink ${ }^{1,2}$, Pieter van 't Veer $^{2}$, Daniel Tomé ${ }^{2,4}$, Stephan J. L. Bakker ${ }^{1,5}$, \\ Marleen A. van Baak ${ }^{1,6}$ and Johanna M. Geleijnse ${ }^{1,2}$ \\ ${ }^{1}$ Top Institute Food and Nutrition, Wageningen, The Netherlands \\ ${ }^{2}$ Division of Human Nutrition, Wageningen University, PO Box 8129, 6700 EV, Wageningen, The Netherlands \\ ${ }^{3}$ TNO, Zeist, The Netherlands \\ ${ }^{4}$ AgroParisTech, INRA, CNRH-IdF, UMR 914, Nutrition Physiology and Ingestive Behavior, Paris, France \\ ${ }^{5}$ Kidney Center, University Medical Center Groningen and University of Groningen, Groningen, The Netherlands \\ ${ }^{6}$ Department of Human Biology, NUTRIM School for Nutrition, Toxicology and Metabolism, Faculty of Health, Medicine \\ and Life Sciences, Maastricht University, Maastricht, The Netherlands
}

(Submitted 23 May 2012 - Final revision received 8 October 2012 - Accepted 3 December 2012 - First published online 4 March 2013)

\begin{abstract}
In the present controlled, randomised, multiple cross-over dietary intervention study, we aimed to identify potential biomarkers for dietary protein from dairy products, meat and grain, which could be useful to estimate intake of these protein types in epidemiological studies. After $9 \mathrm{~d}$ run-in, thirty men and seventeen women (22 (SD 4) years) received three high-protein diets (aimed at approximately $18 \%$ of energy $(\mathrm{en} \%))$ in random order for 1 week each, with approximately 14 en $\%$ originating from either meat, dairy products or grain. We used a two-step approach to identify biomarkers in urine and plasma. With principal component discriminant analysis, we identified amino acids (AA) from the plasma or urinary AA profile that were distinctive between diets. Subsequently, after pooling total study data, we applied mixed models to estimate the predictive value of those AA for intake of protein types. A very good prediction could be made for the intake of meat protein by a regression model that included urinary carnosine, 1-methylhistidine and 3-methylhistidine (98\% of variation in intake explained). Furthermore, for dietary grain protein, a model that included seven AA (plasma lysine, valine, threonine, $\alpha$-aminobutyric acid, proline, ornithine and arginine) made a good prediction (75\% of variation explained). We could not identify biomarkers for dairy protein intake. In conclusion, specific combinations of urinary and plasma AA may be potentially useful biomarkers for meat and grain protein intake, respectively. These findings need to be cross-validated in other dietary intervention studies.
\end{abstract}

\section{Key words: Dietary protein types: Biomarkers: Amino acid profile: Principal component discriminant analysis}

There is increasing interest in the role of dietary protein and specific types of protein (e.g. from animal or plant sources) in health and disease ${ }^{(1-4)}$. Observational epidemiological studies in this field often rely on FFQ or dietary recalls to estimate habitual intake of (types of) protein. Such memorybased methods, however, are prone to errors, which can lead to misclassification of participants and could weaken the associations between intake of protein types and health outcomes $^{(5,6)}$. Therefore, markers of intake for these protein types in biological tissues or fluids could provide more objective indices of true intake. Several metabolic compounds, i.e. urinary carnosine ${ }^{(7)}$, 1-methylhistidine $(1-\mathrm{MH})^{(8)}$, 3-methylhistidine $(3-\mathrm{MH})^{(7,8)}$, taurine $\mathrm{e}^{(9,10)}$, sulphate $\mathrm{f}^{(7)}$, creatinine ${ }^{(7)}$ and serum creatine ${ }^{(7,11)}$, have been proposed as biomarkers for meat protein intake (Table 1). Furthermore, the ratio between natural stable isotopes of $\mathrm{N}\left({ }^{14} \mathrm{~N}:{ }^{15} \mathrm{~N}\right)$ may be an indicator for the ratio between plant and animal protein intake ${ }^{(12,13)}$. However, none of these potential biomarkers has sufficiently been validated. Biomarkers for other major protein types, i.e. meat, dairy and grain protein, are lacking.

We conducted a controlled dietary intervention study to identify potential biomarkers for intake of dairy protein, meat protein and grain protein, which could be useful for further epidemiological studies. We focused on these types of protein because these are the main sources of protein in the Dutch population, with approximately $26 \%$ of total protein intake originating from dairy products, $25 \%$ from meat and $18 \%$ from grain ${ }^{(14)}$. The proteins were provided to the participants in a food-based setting in order to mimic a real-life situation.

Abbreviations: 1-MH, 1-methylhistidine; 3-MH, 3-methylhistidine; AA, amino acids; en\%, percentage of energy; PCDA, principal component discriminant analysis. 
Table 1. Overview of postulated biomarkers

Urine

Carnosine

1-MH

3-MH

Taurine

Sulphate

Creatinine

Ratio of natural stable isotopes of $\mathrm{N}\left({ }^{14} \mathrm{~N}:{ }^{15} \mathrm{~N}\right)$

Blood

Creatine
The dipeptide, $\beta$-alanyl-histidine (carnosine), is present in the muscle and the nerve tissues in most vertebrates ${ }^{(7)}$. Because dietary intake of nerve tissues usually is limited, urinary carnosine might be a potential marker of muscle intake from animals ${ }^{(7)}$

$1-\mathrm{MH}$ forms a dipeptide with $\beta$-alanine and anserine ${ }^{(8)}$. Anserine occurs in the skeletal muscle of several species but not in man. Therefore, urinary $1-\mathrm{MH}$ is a potential biomarker for meat protein intake

Urinary excretion of 3-MH has been suggested as a marker of meat consumption because it is synthesised in the muscle of mammals and released and excreted in urine after intake of muscle protein ${ }^{(17)}$

Taurine is present in animal tissues at high levels ${ }^{(9)}$. About $40 \%$ of taurine, fed as such, is recovered in the urine ${ }^{(10)}$

A high content of cysteine and methionine in proteins leads to an increased degradation to sulphate and sulphite by the intestinal microbiota. Since animal proteins are rich in sulphur-containing amino acids, urinary excretion of inorganic sulphate might reflect meat protein intake ${ }^{(7)}$

Meat contains creatine and creatine phosphate, which partially decomposes to creatinine during cooking ${ }^{(7)}$. Urinary creatinine excretion may increase after (cooked) meat intake ${ }^{(7)}$

Cattle urine has shown that there is a depletion of ${ }^{15} \mathrm{~N}$ relative to their diet ${ }^{(12)}$. It has therefore been hypothesised that animals incorporate dietary ${ }^{15} \mathrm{~N}$ preferentially over dietary ${ }^{14} \mathrm{~N}$. Indeed, it has been found that the level of the ${ }^{15} \mathrm{~N}$ stable natural isotope increases by approximately $3 \%$ up every step in the food chain ${ }^{(13)}$. Possibly, the proportion of ${ }^{15} \mathrm{~N}$ in urine reflects the ratio of animal and plant protein in the diet. However, data on this subject are scarce

Meat contains creatine and creatine phosphate ${ }^{(7)}$. In a study of sixty male and female vegetarians and ninety-nine age-matched omnivores, omnivorous individuals had a higher serum creatine compared with the vegetarians $^{(7,11,21)}$. Therefore, plasma creatine might be a biomarker for meat protein intake

1-MH, 1-methylhistidine; 3-MH, 3-methylhistidine.

\section{Materials and methods}

\section{Study population}

Participants were recruited within a $10-\mathrm{km}$ radius from the university campus. Men and women aged between 18 and 40 years, with a BMI between 18.5 and $30 \mathrm{~kg} / \mathrm{m}^{2}$, were invited to participate. We used questionnaires to collect information about the general characteristics and the medical status. Individuals suffering from chronic disease(s) or using prescribed medication were excluded. We also excluded women who were pregnant, lactating or not using oral contraceptives. Liver and kidney function markers were checked for abnormalities in a fasted blood sample before the start of the study.

\section{Study design}

The Biomarker Study was a controlled, randomised, multiple cross-over dietary intervention study, which was conducted between 21 March and 20 April 2011 at the Wageningen University, The Netherlands. We aimed to explore whether new biomarkers for protein from dairy products, meat and grain could be identified, and whether postulated biomarkers for these types of protein could be confirmed. Because the expected standard deviation of potential new biomarkers was not known, we estimated the necessary study size from the study size of comparable studies $\left(n 24^{(15)}\right.$ and $\left.n 12^{(16)}\right)$. Furthermore, we conducted a power calculation based on 3-MH, one of the postulated biomarkers. In a study carried out on thirty-two participants, urinary 3-MH excretion increased with $1.34 \mu \mathrm{mol} / \mathrm{g}$ of dietary protein (mainly from meat) after $1 \mathrm{~d}$ of altered intake ${ }^{(17)}$. With a difference in meat protein intake of $10 \mathrm{~g}$ and a standard deviation of $21 \mu \mathrm{mol} 3-\mathrm{MH}$, we expected twenty-one participants to be needed (power $\left.80 \%, P=0.05, n 7.9 \times(\mathrm{sD} / D)^{2}\right)$. To allow for drop out and uncertainty with regard to the new biomarkers, we included a total of thirty participants in the present study.
An overview of the study design is given in Fig. 1. The study lasted for $30 \mathrm{~d}$ and consisted of four dietary periods: a run-in period of $9 \mathrm{~d}$ and three subsequent intervention periods of $7 \mathrm{~d}$ each that were applied in random order. The participants were allocated to one of the six diet orders by block randomisation, with a block size of five and with stratification for sex. On the last day of each treatment period, urine was collected for $24 \mathrm{~h}$ and a fasting blood sample was taken. The present study was conducted according to the guidelines laid down in the Declaration of Helsinki, and all procedures involving human participants were approved by the medical ethics committee of the Wageningen University. Written informed consent was obtained from all the participants. The design and aim of the study was registered in the NIH clinical trial database (ClinicalTrials.gov number. NCT01314040).

\section{Dietary intervention}

Menus were designed for ten levels of energy intake, ranging from 7 to $16 \mathrm{MJ} / \mathrm{d}$. The participants were allocated to an energy intake level close to their habitual energy intake, which was estimated before the start of the study using an $\mathrm{FFQ}^{(18)}$. From Monday to Friday, participants consumed their hot meal at lunchtime at the Wageningen University, supervised by dietitians who ensured that the complete meal was consumed. Breakfast, bread meals, snacks, beverages and all meals for Saturdays and Sundays were provided in take-home packages. Participants were carefully instructed on how to prepare the hot meals during the weekends. When participants had incidentally increased energy requirements, e.g. because of sports, a bread bun $(500 \mathrm{~kJ} / \mathrm{bun})$ was provided with the same relative macronutrient composition as the intervention diet of the participant. During the whole study, we supplied $90 \%$ of daily energy intake to the participants. To cover the remaining $10 \%$ of daily energy needs, participants were obliged to choose foods that were 


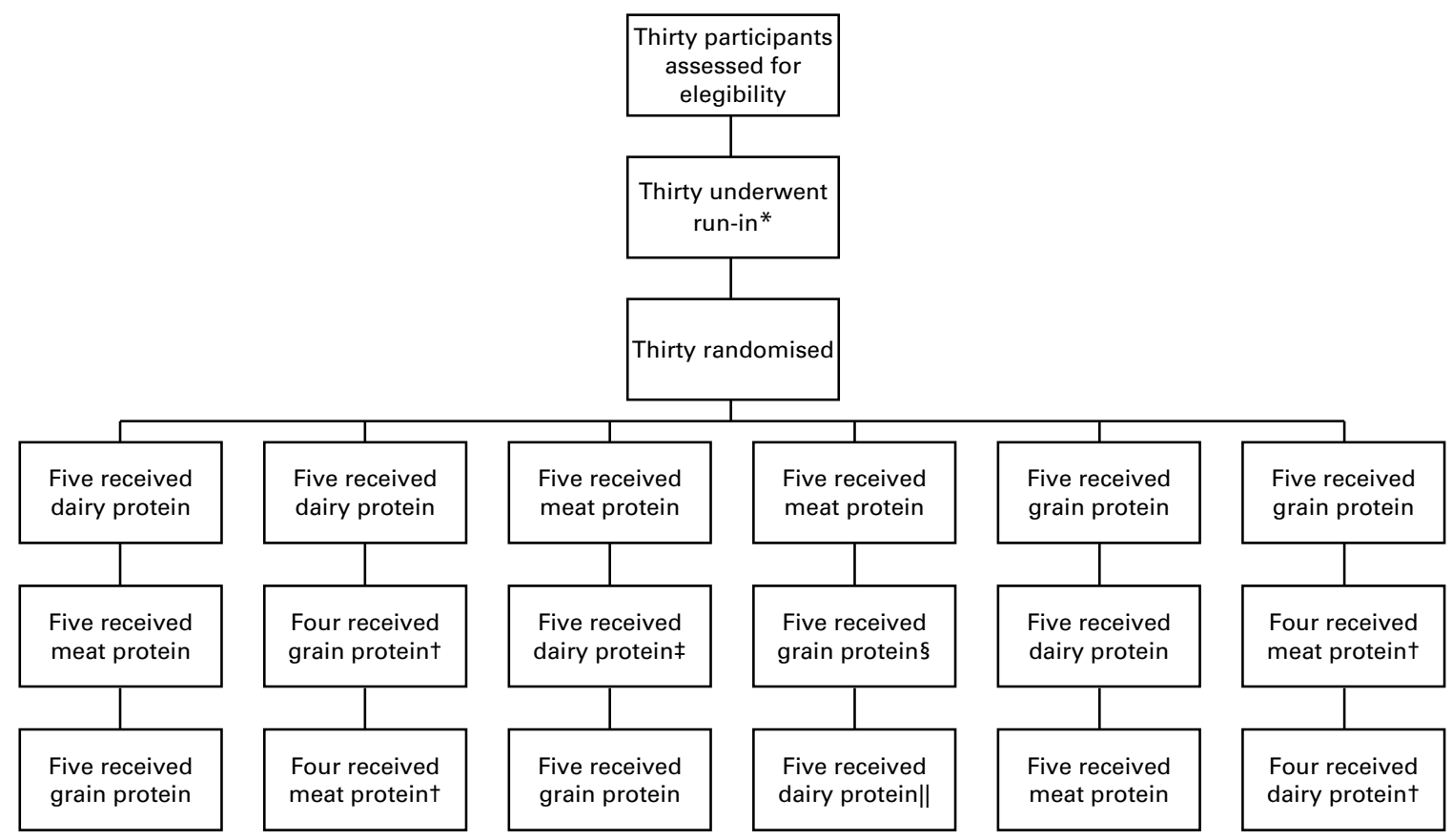

Fig. 1. Flow diagram of participants in the Biomarker Study. After $9 \mathrm{~d}$ run-in, participants were randomised in one of six diet orders. Each intervention diet was consumed for $7 \mathrm{~d}$. The run-in diet was aimed at approximately $15 \%$ of energy (en\%) protein, whereas the intervention diets were aimed at approximately 18 en\% protein, of which approximately $14 \mathrm{en} \%$ originated from the source of interest. After each dietary period, $24 \mathrm{~h}$ urine and blood were collected. * Urine data of the run-in period of one participant were excluded because he reported incomplete urine collection. †Two participants (a man and a woman) discontinued the intervention because of difficulties with the fact that they were not allowed to choose their own food. $¥$ The data of the dairy protein period of one participant were excluded from analysis because of a $130 \%$ higher nitrogen excretion than expected, based on chemical analysis of the diet. § The data of the grain protein period of one participant were excluded because of knee surgery on the day before collection. \|The urine data of the dairy protein period of one participant were excluded because of a mistake in urine handling.

low in protein content $(<0.6 \mathrm{~g}$ protein per portion) from a restricted list. They recorded these foods in a diary in which they also noted any deviations from the study protocol. Body weight was measured twice every week with indoor clothing, without shoes and with empty pockets on a digital balance accurate to $0 \cdot 1 \mathrm{~kg}$ (Seck Bascule, MT). If necessary, energy intake was adjusted to limit changes in weight to less than $0 \cdot 2 \mathrm{~kg}$.

\section{Diet composition and chemical analyses of duplicate portions}

The total protein content of the run-in diet was aimed at $15 \%$ of energy $(\mathrm{en} \%)$. The intervention diets had a protein content aimed at approximately $18 \mathrm{en} \%$, with approximately $14 \mathrm{en} \%$ coming from either dairy products, meat or grain. During the dairy protein-based diet, the main sources of protein were milk and milk products, yoghurt and cheese. In addition, a whey protein isolate was added to the dessert (approximately 4 en $\%$; Nectar, Syntrax). In the meat protein-based diet, the main protein sources were pork, beef and chicken. The main protein sources in the grain protein-based diet were wheat, bran, rice and maize. Additionally, the diet contained legumes (chickpeas, lentils), contributing 3.6 en $\%$ of protein. A wheat protein isolate was added to the dessert, the dressing and the drink (approximately 7 en\%; Ultimate Nutrition, Inc.).

Duplicate portions of each intervention diet, with an energy level of $11 \mathrm{MJ}$, were collected daily and analysed for energy, fat, DM, ash and dietary fibre, according to the official methods of analysis (Association of Official Analytical Chemists) ${ }^{(19)}$. Furthermore, $\mathrm{N}$ was determined by the Kjeldahl method (Kjeltec 2300; Foss), and the amount of protein was calculated using a conversion factor of 6.25. Carbohydrate content of the diets was calculated by difference.

Amino acid (AA) composition was measured using ionexchange chromatography and derivatised post-column (TRIS/AZA, JEOL AminoTac JLC/500-V; Jeol), after hydrolysis of the samples with $\mathrm{HCl}(6 \mathrm{~mol} / \mathrm{l})$ using norvaline as internal standard. Detection was performed at $570 \mathrm{~nm}$ (proline at $440 \mathrm{~nm}$ ). For the determination of cystine and methionine, hydrolysis was preceded by oxidation with performic acid. For analysis of tryptophan, samples were hydrolysed by heating at $119^{\circ} \mathrm{C}$ in a $\mathrm{N}_{2}$ atmosphere with barium hydroxide solution using 5-methyl tryptophan as internal standard. Samples were analysed by HPLC (HPLC-pump: Waters 616, autosampler Waters 717; Waters Corporation) with fluorescence detection, excitation at $300 \mathrm{~nm}$ and emission at 330 nm (fluorescence detector: Jasco FP-1520; Jasco Benelux b.v.; column: Nucleosil C18, PN 89161; Grace Davison Discovery Science). The nutrients in the free-choice items were calculated (NEVO, 2006 ${ }^{(20)}$ ) and added to the analysed values (Table 2 ).

Because the actual intake of total protein did not exactly meet the target intake, leading to differences across the diet periods, we adjusted all our analyses for $\mathrm{N}$ excretion, so that biomarkers for protein types could be identified independent of protein quantity of the diets. 
Table 2. Mean daily intakes* of energy, macronutrients and amino acids by thirty participants during the Biomarker Study

\begin{tabular}{|c|c|c|c|c|c|c|c|c|}
\hline & \multicolumn{2}{|c|}{ Run-in } & \multicolumn{2}{|c|}{ Dairy protein-based diet } & \multicolumn{2}{|c|}{ Meat protein-based diet } & \multicolumn{2}{|c|}{ Grain protein-based diet } \\
\hline & $\begin{array}{l}\text { Mean intake } \\
(\mathrm{en} \%)\end{array}$ & $\begin{array}{l}\text { Mean intake } \\
(\mathrm{g} / \mathrm{kg} \text { per d) }\end{array}$ & $\begin{array}{l}\text { Mean intake } \\
(\mathrm{en} \%)\end{array}$ & $\begin{array}{l}\text { Mean intake } \\
\text { (g/kg per d) }\end{array}$ & $\begin{array}{l}\text { Mean intake } \\
(\text { en\%) }\end{array}$ & $\begin{array}{l}\text { Mean intake } \\
(\mathrm{g} / \mathrm{kg} \text { per } \mathrm{d})\end{array}$ & $\begin{array}{l}\text { Mean intake } \\
(\mathrm{en} \%)\end{array}$ & $\begin{array}{l}\text { Mean intake } \\
\text { (g/kg per d) }\end{array}$ \\
\hline Energy (MJ/d) & \multicolumn{2}{|c|}{$10 \cdot 9$} & \multirow{2}{*}{\multicolumn{2}{|c|}{$11 \cdot 1$}} & \multirow{2}{*}{\multicolumn{2}{|c|}{$11 \cdot 0$}} & \multirow{2}{*}{\multicolumn{2}{|c|}{11.1}} \\
\hline Macronutrients & & & & & & & & \\
\hline Total protein (analysed) & $15 \cdot 1$ & 1.4 & $19 \cdot 1$ & 1.8 & 22.5 & $2 \cdot 1$ & $16 \cdot 7$ & 1.6 \\
\hline Animal protein $\dagger$ & 9.2 & 0.9 & $15 \cdot 9$ & 1.5 & $17 \cdot 2$ & 1.6 & $3 \cdot 1$ & 0.3 \\
\hline Dairy proteint & $4 \cdot 4$ & 0.4 & $15 \cdot 2$ & 1.4 & $1 . \overline{5}$ & 0.1 & 1.5 & 0.1 \\
\hline Meat proteint & 4.5 & 0.4 & 1.2 & 0.1 & $15 \cdot 7$ & 1.5 & 1.5 & 0.1 \\
\hline Plant protein $\dagger$ & 4.9 & 0.5 & 3.3 & 0.3 & 3.7 & 0.3 & $15 \cdot 6$ & 1.5 \\
\hline Grain protein $†$ & 4.3 & 0.4 & 1.3 & 0.1 & 1.5 & 0.1 & $14 \cdot 2 \ddagger$ & 1.3 \\
\hline Fat & 30.4 & 1.3 & 30.9 & 1.3 & 29.9 & 1.3 & $27 \cdot 8$ & 1.2 \\
\hline \multirow[t]{2}{*}{ Carbohydrate } & 53.0 & 4.9 & $48 \cdot 5$ & 4.6 & 43.0 & $4 \cdot 1$ & $54 \cdot 1$ & $5 \cdot 1$ \\
\hline & $\begin{array}{r}\text { Mean intake } \\
\quad \text { (protein \%) }\end{array}$ & $\begin{array}{l}\text { Mean intake } \\
(\mathrm{mg} / \mathrm{kg} \text { per } \mathrm{d})\end{array}$ & $\begin{array}{r}\text { Mean intake } \\
\quad(\text { protein \%) }\end{array}$ & $\begin{array}{l}\text { Mean intake } \\
(\mathrm{mg} / \mathrm{kg} \text { per } \mathrm{d})\end{array}$ & $\begin{array}{r}\text { Mean intake } \\
\text { (protein \%) }\end{array}$ & $\begin{array}{l}\text { Mean intake } \\
(\mathrm{mg} / \mathrm{kg} \text { per } \mathrm{d})\end{array}$ & $\begin{array}{l}\text { Mean intake } \\
\text { (protein \%) }\end{array}$ & $\begin{array}{l}\text { Mean intake } \\
(\mathrm{mg} / \mathrm{kg} \text { per } \mathrm{d})\end{array}$ \\
\hline \multicolumn{9}{|l|}{ Amino acids } \\
\hline $\mathrm{He}$ & $4 \cdot 3$ & 60 & $5 \cdot 3$ & 96 & 4.3 & 92 & 3.7 & 59 \\
\hline Leu & 7.8 & 110 & $9 \cdot 8$ & 177 & 7.5 & 160 & $7 \cdot 1$ & 112 \\
\hline Lys & $6 \cdot 2$ & 87 & $8 \cdot 1$ & 146 & $7 \cdot 4$ & 158 & 3.4 & 53 \\
\hline Met & $2 \cdot 2$ & 31 & $2 \cdot 5$ & 45 & $2 \cdot 4$ & 51 & 1.8 & 28 \\
\hline Cys & 1.3 & 18 & 1.4 & 25 & 1.0 & 22 & 1.9 & 30 \\
\hline Phe & 4.4 & 61 & 4.6 & 84 & 3.9 & 82 & 4.7 & 74 \\
\hline Tyr & 3.5 & 49 & 4.3 & 78 & 3.0 & 63 & 3.2 & 51 \\
\hline Thr & 3.8 & 53 & 4.9 & 88 & 4.0 & 86 & $3 \cdot 1$ & 49 \\
\hline Trp & 1.2 & 17 & 1.5 & 27 & 1.2 & 25 & 1.1 & 18 \\
\hline Val & 5.0 & 70 & $6 \cdot 1$ & 110 & 4.8 & 101 & 4.4 & 69 \\
\hline $\mathrm{Arg}$ & 4.9 & 69 & 3.9 & 71 & 5.7 & 121 & 4.6 & 73 \\
\hline His & $2 \cdot 7$ & 38 & 2.5 & 46 & 3.0 & 64 & $2 \cdot 2$ & 35 \\
\hline Ala & 4.3 & 60 & 4.2 & 76 & 5.2 & 111 & 3.6 & 56 \\
\hline Asp & $7 \cdot 7$ & 108 & 9.4 & 170 & 8.9 & 189 & 5.7 & 90 \\
\hline Glu & 20.9 & 293 & 21.7 & 391 & $16 \cdot 3$ & 346 & 27.9 & 440 \\
\hline Gly & 3.7 & 52 & $2 \cdot 7$ & 49 & 4.7 & 99 & 4.0 & 63 \\
\hline Pro & $7 \cdot 2$ & 102 & 9.0 & 163 & 5.0 & 106 & 9.6 & 151 \\
\hline Ser & 4.4 & 62 & $5 \cdot 3$ & 95 & 3.9 & 82 & 4.6 & 73 \\
\hline
\end{tabular}

en\%, Percentage of energy; protein \%, percentage of total protein intake.
*Mean nutrient intakes were calculated from chemically analysed values of duplicate portions of each diet with an energy level of 11 MJ. The nutrients of the free-choice low-protein items were calculated (NEVO, 2006 ${ }^{(20)}$ ) and added to the analysed values.

† Mean nutrient intake was only based on the calculated nutrient content of foods because types of protein cannot be distinguished in chemical analysis.

$\ddagger 3.6$ en $\%$ of protein came from chickpeas and lentils (food based). 


\section{Urine sampling and analysis}

Urine was collected during $24 \mathrm{~h}$ at the final day of the run-in period and each intervention period. Before collection, $3 \mathrm{ml}$ of chlorhexidine digluconate $(19-21 \% \mathrm{~m} / \mathrm{V})$ was added to each 2 litre urine container as a preservative. Participants were instructed to discard the first voiding in the morning after waking up and to note the time. Subsequently, they collected all the urine up to and including the voiding on the same time the next day. Urine was kept cool in a cooling bag with a cooling element during the $24 \mathrm{~h}$ collection. Subsequently, urine samples were stored at $-80^{\circ} \mathrm{C}$ until analyses. Total $\mathrm{N}$ was analysed by the Kjeldahl method (Kjeltec 2300; Foss) and used as a marker of dietary compliance. Expected $24 \mathrm{~h} \mathrm{~N}$ excretion was calculated as total daily protein intake (as obtained from chemical analyses of duplicate portions) divided by $6 \cdot 25$. Because urinary $\mathrm{N}$ reflects approximately $80 \%$ of protein intake ${ }^{(21)}$, the resulting number was multiplied by $1 \cdot 25$. Participants with $50 \%$ higher or lower $\mathrm{N}$ excretion than expected were considered to be non-compliant and excluded from the analysis.

Urinary creatinine was analysed by the Jaffé reaction using reagents from Roche Diagnostics on a Roche-Hitachi Modular P device (Roche). Furthermore, the levels of urinary AA were analysed by a triple-quadrupole mass spectrometer (type API 4000; AB SCIEX) after separation of AA by isocratic HPLC (Agilent 1100LC; Agilent Technologies Deutschland $\mathrm{GmbH})$. Isotope analysis $\left({ }^{14} \mathrm{~N} /{ }^{15} \mathrm{~N}\right)$ was conducted by Europe 20/20 Stable Isotope Analyser coupled with a ${ }^{15} \mathrm{~N}$ sample combustion unit (Europa Scientific Limited).

\section{Blood sampling and analysis}

At the final morning of each study period, a fasting blood sample was obtained from the antecubital vein of the forearm. From 22.00 hours the evening before, participants were not allowed to consume foods or drinks except for water. Blood was sampled in vacutainer tubes (BD Vacutainer) containing clot activator for serum and in tubes containing potassium ethylene diamine tetra acid for plasma. Potassium ethylene diamine tetra acid plasma tubes were ice-chilled and centrifuged for $10 \mathrm{~min}$ at $1190 \mathrm{~g}$ at $4^{\circ} \mathrm{C}$, within $60 \mathrm{~min}$ after venepuncture. Serum tubes were stored in the dark for approximately $1.5 \mathrm{~h}$ and then centrifuged for $10 \mathrm{~min}$ at $1550 \mathrm{~g}$ at $20^{\circ} \mathrm{C}$. Plasma and urine samples were stored at $-80^{\circ} \mathrm{C}$ until analysis.

Creatine in the serum was analysed using the Barrit reaction after addition of 1-naphthol and photometrically quantified at $546 \mathrm{~nm}$ (Hitachi U-1800 spectrophotometer; Hitachi High-Technologies Europe $\mathrm{GmbH}$ ). Finally, AA profile in plasma was analysed by a triple-quadrupole mass spectrometer (type API 4000; AB SCIEX) after separation of AA by isocratic HPLC (Agilent 1100LC; Agilent Technologies Deutschland $\mathrm{GmbH})$.

\section{Statistical analysis}

To identify biomarkers that may be useful to estimate the intake of protein types, we used a two-step approach. With principal component discriminant analysis (PCDA), we identified AA from the urinary and plasma AA profiles that were distinctive between the diets. For individual biomarkers that did not belong to the AA profile (i.e. urinary creatinine, sulphate, $\%{ }^{15} \mathrm{~N}$ and serum creatine), we investigated whether there were differences between intervention diets using ANCOVA. As a second step, we applied mixed models after pooling total study data to estimate the predictive value of selected AA and individual biomarkers for intake of protein types.

PCDA were performed in the Matlab environment (R2008b, 1984-8; The Mathworks, Inc.) using the PLS toolbox for Matlab version 5.0.3 ( $r$ 6466, 1995-8; Eigenvector Research, Inc.). We performed ANCOVA and mixed models using the SAS statistical software package (SAS version 9.2; SAS Institute).

\section{Preparation of data}

Urinary excretion data of AA and sulphate were adjusted for creatinine excretion to account for potential incompleteness of the $24 \mathrm{~h}$ urine collections. Furthermore, these data were adjusted for total $\mathrm{N}$ excretion to take into account the unintended differences in protein content of intervention diets that were revealed by chemical analysis of the duplicate portions. Plasma AA levels and serum creatine were not correlated to total protein intake and were, therefore, not adjusted for differences in the protein content of the diets. Missing data due to levels below the detection limit were replaced by detection limit divided by two. For PCDA of AA profiles, levels of AA were calculated relative to the run-in period $(($ diet-run-in)/run-in $\times 100)$ and data were mean-centred per person to remove the between-subject variation. Furthermore, auto-scaling of all AA was performed by dividing the values by their own standard deviation.

\section{Identification of amino acids that are distinctive between diets}

Principal component analysis ${ }^{(22)}$ was used to screen all data sets in order to detect outliers or patterns present in the data. PCDA classification was applied to investigate diet differences. The validity of the PCDA model was tested using a ten-fold Venetian blind cross-validation. This resulted in a percentage of samples that could be classified in the right diet based on the urinary or plasma AA profiles.

In PCDA, loadings of the discriminant (a linear combination of all AA from the profile) reflect the influence of the original variables on differences between diets, which allowed us to identify specific AA that might be distinctive for intake of one of the protein types of interest ${ }^{(23,24)}$. We considered loadings $>4$ for further analysis.

\section{Identification of individual biomarkers that are different between diets}

For individual biomarkers that did not belong to the AA profile (i.e. urinary creatinine, sulphate, $\% 0^{15} \mathrm{~N}$ and serum creatine), we investigated whether there were differences between intervention diets using ANCOVA. Because of non-normality, data were log-transformed. In case a significant diet effect 
Table 3. Overview of mean amino acid intake (adjusted for total protein intake), plasma levels and urinary excretion (adjusted for total nitrogen excretion and creatinine excretion) of thirty participants in the Biomarker Study (Mean values with their standard errors)

\begin{tabular}{|c|c|c|c|c|c|c|}
\hline & \multicolumn{2}{|c|}{$\begin{array}{l}\text { Dairy protein- } \\
\text { based diet }\end{array}$} & \multicolumn{2}{|c|}{$\begin{array}{l}\text { Meat protein- } \\
\text { based diet }\end{array}$} & \multicolumn{2}{|c|}{$\begin{array}{c}\text { Grain protein- } \\
\text { based diet }\end{array}$} \\
\hline & Mean & SE & Mean & SE & Mean & SE \\
\hline Total energy $(\mathrm{MJ} / \mathrm{d})$ & \multicolumn{2}{|c|}{$11 \cdot 1$} & \multicolumn{2}{|c|}{$11 \cdot 0$} & \multicolumn{2}{|c|}{$11 \cdot 1$} \\
\hline Total protein $(\mathrm{g} / \mathrm{kg}$ per $\mathrm{d})$ & \multicolumn{2}{|c|}{1.8} & \multicolumn{2}{|c|}{$2 \cdot 1$} & \multicolumn{2}{|c|}{1.6} \\
\hline Total $\mathrm{N}$ excretion & $16 \cdot 5$ & 0.8 & $18 \cdot 9$ & 0.9 & $14 \cdot 1$ & 0.7 \\
\hline \multicolumn{7}{|l|}{$\begin{array}{l}\text { Dietary amino acids } \\
\text { lle }\end{array}$} \\
\hline Intake $(\mathrm{mg} / \mathrm{kg} \text { per } \mathrm{d})^{\star}$ & \multicolumn{2}{|c|}{$95 \cdot 1$} & \multicolumn{2}{|c|}{$86 \cdot 6$} & \multicolumn{2}{|c|}{61.0} \\
\hline Plasma levels (mg/l) & 8.6 & 0.3 & 8.4 & 0.3 & $8 \cdot 4$ & 0.3 \\
\hline Urinary excretion (mg/24h) & $1 \cdot 6$ & 0.1 & $1 \cdot 6$ & $0 \cdot 1$ & $1 \cdot 8$ & $0 \cdot 1$ \\
\hline \multicolumn{7}{|l|}{ Leu } \\
\hline Intake $(\mathrm{mg} / \mathrm{kg} \text { per } \mathrm{d})^{\star}$ & & & & & & \\
\hline Plasma levels (mg/l) & $14 \cdot 0$ & 0.6 & 14.5 & 0.6 & $13 \cdot 8$ & 0.6 \\
\hline Urinary excretion $(\mathrm{mg} / 24 \mathrm{~h}) \dagger$ & $5 \cdot 7$ & 0.3 & 4.7 & 0.3 & 4.5 & 0.3 \\
\hline Lys & & & & & & \\
\hline Intake $(\mathrm{mg} / \mathrm{kg} \text { per } \mathrm{d})^{\star}$ & & & & & & \\
\hline Plasma levels (mg/l) & $26 \cdot 0$ & 0.7 & $26 \cdot 1$ & 0.7 & $19 \cdot 0$ & 0.7 \\
\hline Urinary excretion $(\mathrm{mg} / 24 \mathrm{~h}) \dagger$ & $15 \cdot 2$ & $2 \cdot 7$ & $18 \cdot 3$ & $2 \cdot 6$ & 11.5 & 2.4 \\
\hline Met & & & & & & \\
\hline Intake $(\mathrm{mg} / \mathrm{kg} \text { per } \mathrm{d})^{\star}$ & & & & & & \\
\hline Plasma levels (mg/l) & $4 \cdot 1$ & 0.1 & 3.9 & $0 \cdot 1$ & 4.0 & $0 \cdot 1$ \\
\hline Urinary excretion $(\mathrm{mg} / 24 \mathrm{~h}) \dagger$ & $2 \cdot 6$ & 0.2 & $2 \cdot 7$ & 0.2 & $2 \cdot 6$ & $0 \cdot 1$ \\
\hline Cystine & & & & & & \\
\hline Intake $(\mathrm{mg} / \mathrm{kg} \text { per } \mathrm{d})^{\star}$ & & & & & & \\
\hline Plasma levels (mg/l) & 4.9 & 0.2 & $5 \cdot 1$ & 0.2 & 4.7 & 0.2 \\
\hline Urinary excretion $(\mathrm{mg} / 24 \mathrm{~h}) \dagger$ & $10 \cdot 2$ & 0.5 & 8.9 & 0.5 & $10 \cdot 8$ & 0.4 \\
\hline Phe & & & & & & \\
\hline Intake $(\mathrm{mg} / \mathrm{kg} \text { per } \mathrm{d})^{\star}$ & & & & & & \\
\hline Plasma levels (mg/l) & $9 \cdot 3$ & 0.2 & $8 \cdot 7$ & 0.2 & $8 \cdot 7$ & 0.2 \\
\hline Urinary excretion $(\mathrm{mg} / 24 \mathrm{~h}) \dagger$ & 8.8 & 0.4 & $8 \cdot 1$ & 0.4 & 9.9 & 0.4 \\
\hline Tyr & & & & & & \\
\hline Intake $(\mathrm{mg} / \mathrm{kg} \text { per } \mathrm{d})^{\star}$ & & & & & & \\
\hline Plasma levels (mg/l) & $8 \cdot 1$ & 0.4 & $7 \cdot 4$ & 0.4 & $8 \cdot 2$ & 0.4 \\
\hline Urinary excretion $(\mathrm{mg} / 24 \mathrm{~h}) \dagger$ & $13 \cdot 3$ & $1 \cdot 1$ & $9 \cdot 5$ & $1 \cdot 1$ & $15 \cdot 5$ & $1 \cdot 0$ \\
\hline Thr & & & & & & \\
\hline Intake $(\mathrm{mg} / \mathrm{kg} \text { per } \mathrm{d})^{\star}$ & & & & & & \\
\hline Plasma levels (mg/l) & $17 \cdot 2$ & $0 \cdot 6$ & $17 \cdot 5$ & 0.6 & $13 \cdot 8$ & $0 \cdot 6$ \\
\hline Urinary excretion $(\mathrm{mg} / 24 \mathrm{~h}) \dagger$ & $28 \cdot 0$ & $3 \cdot 2$ & $30 \cdot 6$ & $3 \cdot 1$ & $19 \cdot 6$ & $2 \cdot 9$ \\
\hline Trp & & & & & & \\
\hline Intake $(\mathrm{mg} / \mathrm{kg} \text { per } \mathrm{d})^{\star}$ & & & & & & \\
\hline Plasma levels (mg/l) & $11 \cdot 7$ & 0.3 & $11 \cdot 2$ & 0.3 & $11 \cdot 0$ & 0.3 \\
\hline Urinary excretion $(\mathrm{mg} / 24 \mathrm{~h}) \dagger$ & $13 \cdot 2$ & $1 \cdot 1$ & 11.9 & $1 \cdot 1$ & $13 \cdot 5$ & 1.0 \\
\hline Val & & & & & & \\
\hline Intake $(\mathrm{mg} / \mathrm{kg} \text { per } \mathrm{d})^{\star}$ & & & & & & \\
\hline Plasma levels (mg/l) & $26 \cdot 4$ & 0.8 & $26 \cdot 0$ & 0.8 & $22 \cdot 3$ & 0.8 \\
\hline Urinary excretion $(\mathrm{mg} / 24 \mathrm{~h}) \dagger$ & 7.9 & 0.3 & $6 \cdot 7$ & 0.3 & $6 \cdot 3$ & 0.3 \\
\hline Arg & & & & & & \\
\hline Intake $(\mathrm{mg} / \mathrm{kg} \text { per } \mathrm{d})^{*}$ & & & & & & \\
\hline Plasma levels (mg/l) & $13 \cdot 4$ & 0.5 & $13 \cdot 7$ & 0.5 & $15 \cdot 0$ & 0.5 \\
\hline Urinary excretion $(\mathrm{mg} / 24 \mathrm{~h}) \dagger$ & 4.4 & 0.2 & 3.5 & 0.2 & 2.9 & 0.2 \\
\hline His & & & & & & \\
\hline Intake $(\mathrm{mg} / \mathrm{kg} \text { per } \mathrm{d})^{\star}$ & & & & & & \\
\hline Plasma levels (mg/l) & $12 \cdot 6$ & 0.4 & $13 \cdot 3$ & 0.4 & $12 \cdot 8$ & 0.4 \\
\hline Urinary excretion $(\mathrm{mg} / 24 \mathrm{~h}) \dagger$ & $109 \cdot 2$ & $11 \cdot 2$ & $138 \cdot 1$ & $10 \cdot 8$ & $128 \cdot 5$ & $10 \cdot 2$ \\
\hline Ala & & & & & & \\
\hline Intake $(\mathrm{mg} / \mathrm{kg} \text { per } \mathrm{d})^{\star}$ & & & & & & \\
\hline Plasma levels (mg/l) & $28 \cdot 6$ & $1 \cdot 1$ & 28.4 & $1 \cdot 1$ & $29 \cdot 4$ & $1 \cdot 1$ \\
\hline Urinary excretion $(\mathrm{mg} / 24 \mathrm{~h}) \dagger$ & 31.4 & $2 \cdot 6$ & $29 \cdot 3$ & 2.5 & $31 \cdot 2$ & $2 \cdot 3$ \\
\hline Asp & & & & & & \\
\hline Intake $(\mathrm{mg} / \mathrm{kg} \text { per } \mathrm{d})^{\star}$ & & & & & & \\
\hline Plasma levels (mg/l) & $1 \cdot 0$ & 0.1 & $1 \cdot 1$ & $0 \cdot 1$ & 0.9 & $0 \cdot 1$ \\
\hline Urinary excretion $(\mathrm{mg} / 24 \mathrm{~h}) \dagger$ & 1.4 & 0.1 & 1.3 & 0.1 & 1.0 & $0 \cdot 1$ \\
\hline Asn & & & & & & \\
\hline Plasma levels (mg/l) & $7 \cdot 0$ & $0 \cdot 2$ & $6 \cdot 8$ & 0.2 & 6.5 & 0.2 \\
\hline Urinary excretion $(\mathrm{mg} / 24 \mathrm{~h}) \dagger$ & $19 \cdot 8$ & $3 \cdot 2$ & $20 \cdot 4$ & $3 \cdot 1$ & $15 \cdot 0$ & $2 \cdot 9$ \\
\hline
\end{tabular}


Table 3. Continued

\begin{tabular}{|c|c|c|c|c|c|c|}
\hline & \multicolumn{2}{|c|}{$\begin{array}{c}\text { Dairy protein- } \\
\text { based diet }\end{array}$} & \multicolumn{2}{|c|}{$\begin{array}{c}\text { Meat protein- } \\
\text { based diet }\end{array}$} & \multicolumn{2}{|c|}{$\begin{array}{c}\text { Grain protein- } \\
\text { based diet }\end{array}$} \\
\hline & Mean & SE & Mean & SE & Mean & SE \\
\hline \multicolumn{7}{|l|}{ Glu } \\
\hline Intake $(\mathrm{mg} / \mathrm{kg} \text { per } \mathrm{d})^{\star}$ & \multicolumn{2}{|c|}{$384 \cdot 8$} & \multicolumn{2}{|c|}{$319 \cdot 4$} & \multicolumn{2}{|c|}{$449 \cdot 2$} \\
\hline Plasma levels (mg/l) & $8 \cdot 7$ & 0.4 & $9 \cdot 0$ & 0.4 & 8.9 & 0.4 \\
\hline Urinary excretion $(\mathrm{mg} / 24 \mathrm{~h}) \dagger$ & $7 \cdot 0$ & 0.4 & $6 \cdot 8$ & 0.4 & $6 \cdot 1$ & 0.4 \\
\hline \multicolumn{7}{|l|}{ Gln } \\
\hline Plasma levels (mg/l) & $72 \cdot 6$ & $2 \cdot 5$ & $71 \cdot 8$ & 2.5 & 74.8 & 2.5 \\
\hline Urinary excretion $(\mathrm{mg} / 24 \mathrm{~h}) \dagger$ & 121.4 & $7 \cdot 7$ & $113 \cdot 6$ & $7 \cdot 4$ & $126 \cdot 8$ & $7 \cdot 0$ \\
\hline \multicolumn{7}{|l|}{ Gly } \\
\hline Intake $(\mathrm{mg} / \mathrm{kg} \text { per } \mathrm{d})^{\star}$ & \multicolumn{2}{|c|}{48.5} & \multicolumn{2}{|c|}{$95 \cdot 0$} & \multicolumn{2}{|c|}{$64 \cdot 1$} \\
\hline Plasma levels (mg/l) & 12.5 & 0.7 & $13 \cdot 6$ & 0.7 & $14 \cdot 3$ & 0.7 \\
\hline Urinary excretion $(\mathrm{mg} / 24 \mathrm{~h}) \dagger$ & $75 \cdot 7$ & $6 \cdot 7$ & $81 \cdot 0$ & $6 \cdot 4$ & $88 \cdot 3$ & $6 \cdot 1$ \\
\hline \multicolumn{7}{|l|}{ Pro } \\
\hline Intake $(\mathrm{mg} / \mathrm{kg} \text { per } \mathrm{d})^{\star}$ & \multicolumn{2}{|c|}{$160 \cdot 4$} & \multicolumn{2}{|c|}{$97 \cdot 3$} & \multicolumn{2}{|c|}{154.1} \\
\hline Plasma levels (mg/l) & 24.5 & $1 \cdot 1$ & 19.5 & $1 \cdot 1$ & $28 \cdot 3$ & $1 \cdot 1$ \\
\hline Urinary excretion $(\mathrm{mg} / 24 \mathrm{~h}) \dagger$ & 1.7 & 0.2 & $1 \cdot 2$ & 0.2 & $2 \cdot 0$ & 0.2 \\
\hline \multicolumn{7}{|l|}{ Ser } \\
\hline Intake $(\mathrm{mg} / \mathrm{kg} \text { per } \mathrm{d})^{\star}$ & \multicolumn{2}{|c|}{93.5} & \multicolumn{2}{|c|}{$76 \cdot 9$} & \multicolumn{2}{|c|}{74.5} \\
\hline Plasma levels (mg/l) & $10 \cdot 6$ & 0.5 & 11.9 & 0.5 & 11.9 & 0.5 \\
\hline Urinary excretion $(\mathrm{mg} / 24 \mathrm{~h}) \dagger$ & $43 \cdot 4$ & $3 \cdot 4$ & 44.9 & $3 \cdot 3$ & $48 \cdot 4$ & $3 \cdot 1$ \\
\hline \multicolumn{7}{|l|}{ Metabolites } \\
\hline \multicolumn{7}{|l|}{ Orn } \\
\hline Plasma levels (mg/l) & $4 \cdot 1$ & 0.3 & $4 \cdot 2$ & 0.3 & 4.9 & 0.3 \\
\hline Urinary excretion $(\mathrm{mg} / 24 \mathrm{~h}) \dagger$ & 1.5 & $0 \cdot 1$ & $1 \cdot 3$ & $0 \cdot 1$ & 1.6 & $0 \cdot 1$ \\
\hline \multicolumn{7}{|l|}{ Cit } \\
\hline Plasma levels (mg/l) & $4 \cdot 7$ & 0.2 & $4 \cdot 7$ & 0.2 & 4.7 & 0.2 \\
\hline Urinary excretion $(\mathrm{mg} / 24 \mathrm{~h}) \dagger$ & 1.0 & $0 \cdot 1$ & 1.2 & $0 \cdot 1$ & 1.0 & $0 \cdot 1$ \\
\hline Нур & & & & & & \\
\hline Plasma levels (mg/l) & $1 \cdot 1$ & $0 \cdot 1$ & $2 \cdot 2$ & 0.1 & 1.5 & 0.1 \\
\hline Urinary excretion $(\mathrm{mg} / 24 \mathrm{~h}) \dagger$ & 1.0 & $0 \cdot 1$ & 1.0 & $0 \cdot 1$ & 1.0 & $0 \cdot 1$ \\
\hline Pea & & & & & & \\
\hline Plasma levels (mg/l) & 1.0 & 0.1 & $1 \cdot 1$ & $0 \cdot 1$ & $1 \cdot 1$ & $0 \cdot 1$ \\
\hline Urinary excretion $(\mathrm{mg} / 24 \mathrm{~h}) \dagger$ & $3 \cdot 2$ & 0.3 & $3 \cdot 6$ & 0.3 & 3.0 & 0.3 \\
\hline Abu & & & & & & \\
\hline Plasma levels (mg/l) & $2 \cdot 1$ & 0.1 & $2 \cdot 3$ & $0 \cdot 1$ & 1.6 & $0 \cdot 1$ \\
\hline Urinary excretion $(\mathrm{mg} / 24 \mathrm{~h}) \dagger$ & 1.7 & 0.2 & 1.6 & 0.2 & 1.7 & 0.1 \\
\hline Tau & & & & & & \\
\hline Plasma levels (mg/l) & $14 \cdot 0$ & 1.0 & 14 & 1.0 & 13 & 1.0 \\
\hline Urinary excretion $(\mathrm{mg} / 24 \mathrm{~h}) \dagger$ & $63 \cdot 7$ & 29.5 & $125 \cdot 6$ & 28.4 & $88 \cdot 2$ & $26 \cdot 7$ \\
\hline Sar & & & & & & \\
\hline Urinary excretion $(\mathrm{mg} / 24 \mathrm{~h}) \dagger$ & $1 \cdot 0$ & $0 \cdot 1$ & $1 \cdot 0$ & 0.1 & 1.0 & $0 \cdot 1$ \\
\hline Car & & & & & & \\
\hline $\begin{array}{l}\text { Urinary excretion }(\mathrm{mg} / 24 \mathrm{~h}) \dagger \\
\text { 1-MH }\end{array}$ & 3.9 & $3 \cdot 1$ & $41 \cdot 1$ & $3 \cdot 0$ & $8 \cdot 6$ & $2 \cdot 8$ \\
\hline Urinary excretion $(\mathrm{mg} / 24 \mathrm{~h}) \dagger$ & $28 \cdot 3$ & $8 \cdot 1$ & $178 \cdot 9$ & $7 \cdot 8$ & $44 \cdot 4$ & $7 \cdot 3$ \\
\hline Urinary excretion $(\mathrm{mg} / 24 \mathrm{~h}) \dagger$ & $36 \cdot 2$ & 2.4 & 81.0 & $2 \cdot 3$ & $44 \cdot 7$ & $2 \cdot 2$ \\
\hline
\end{tabular}

Pea, phosphoethanolamine; 1-MH, 1-Methylhistidine; 3-MH, 3-Methylhistidine.

${ }^{*}$ Adjusted for total protein intake by means of ANCOVA.

†Adjusted for total $\mathrm{N}$ and creatinine excretion by means of ANCOVA.

was found, partial tests, corrected for multiple comparisons using Tukey-Kramer, were used to identify the differences. We considered a two-sided $P$ value $<0.05$ as statistically significant.

\section{Predictive value of selected amino acids and individual markers}

To explore whether AA with a loading $>4$ or individual compounds that were significantly different between diets would be interesting as biomarkers, we evaluated their predictive value for the intake of one of the protein types. We modelled the compounds of interest against intake of protein types using mixed model analysis with participant number as a random factor and data of all diets in one model. Subsequently, we calculated the amount of explained variation in intake using the method of Snijders \& Bosker ${ }^{(25)}$.

\section{Results}

The study involved thirteen men and seventeen women, with a mean age of 22 (SD 4) years and a BMI of 21.6 (SD 2.2) $\mathrm{kg} / \mathrm{m}^{2}$ (Fig. 1). Kidney and liver functions were normal, with mean serum creatinine being 73.3 (SD 9.8) $\mu \mathrm{mol} / \mathrm{l}$, aspartate aminotransferase (ASAT) 29.4 (SD 5.7) $\mu / 1$, alanine 


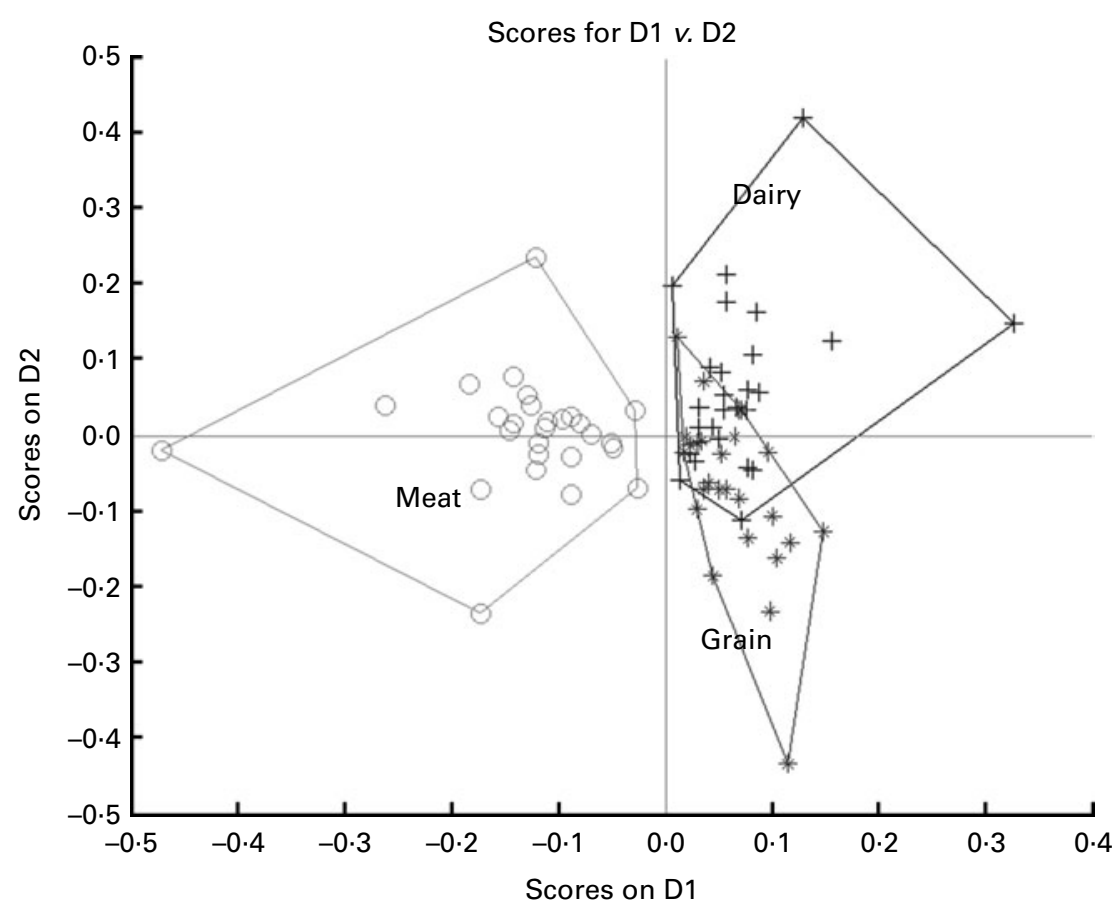

Fig. 2. Principal component discriminant analysis (PCDA) score plot for urinary amino acid profiles of twenty-seven participants in the Biomarker Study. Values of the two discriminant components from PCDA that explained most variation in urinary amino acid profiles. Each dot represents a linear combination of all urinary amino acid levels in one participant during one dietary period. Based on their urinary amino acid profiles, $93 \%$ of participants were correctly classified in the meat protein-based diet, $70 \%$ in the dairy protein-based diet and $80 \%$ in the grain protein-based diet. D1, discriminant 1; D2, discriminant 2.

aminotransferase (ALAT) 18.8 (SD 9.3) $\mu / 1$ and $\gamma$-glutamyltransferase $(\gamma$-GT) 20.5 (SD 11.6) $\mu / 1$. After the first intervention period, one male and one female participant withdrew, because they could no longer adhere to the prescribed diet. Furthermore, for one participant, urine data of the run-in period were excluded from the analysis because he reported incomplete urine collection. For another participant, data of the grain protein period were excluded because of a knee surgery on the day before collection and the data of the dairy protein period of a third participant were excluded because of a $130 \%$ higher $\mathrm{N}$ excretion than expected, based on the chemical analysis of the diet. Finally, for one participant, urine data of the dairy protein period were excluded because of a mistake in urine handling.

In Table 3, AA intake and AA levels in plasma and in urine are shown after adjustment for total protein intake (AA intake) or total $\mathrm{N}$ and creatinine excretion (levels in urine). Baseline values without adjustment are given in supplementary Table S1 (available online). Principal component analysis revealed no sex differences or other patterns that were not due to diet differences.

\section{Identification of urinary amino acids that are distinctive between diets}

The results from PCDA of urinary AA profiles are depicted in Fig. 2. In cross-validation of the PCDA model, $70 \%$ of the participants were correctly classified in the dairy proteinbased diet, $93 \%$ in the meat protein-based diet and $80 \%$ in the grain protein-based diet. The differences between the meat protein-based diet and the other two diets were mainly observed in the values of discriminant 1 . Several of the AA that have been suggested as biomarkers for meat protein had an absolute loading $>4$ in the direction of the meat protein-based diet (i.e. 1-MH, 3-MH and carnosine, Table 4). The AA that had an absolute loading $>4$ in the direction of the other two diets were proline and cysteine. Because in the values of discriminant 2 diets could not be separated, it was not possible to identify the potential biomarkers for the other two diets.

\section{Identification of plasma amino acids that largely influence diet differences}

For the plasma AA profiles, results are depicted in Fig. 3. The percentage of participants that was correctly classified was $86 \%$ for the dairy protein-based diet, $88 \%$ for the meat protein-based diet and $96 \%$ for the grain protein-based diet. The differences between the grain protein based-diet and the other two diets were mainly observed in the values of discriminant 1 , and $\mathrm{AA}$ that had an absolute loading $>4$ in the direction of the grain protein diet were proline, ornithine and arginine (Table 5). AA with an absolute loading in the direction of the other two diets were lysine, valine, threonine and $\alpha$-aminobutyric acid. Because in the values of discriminant 2 diets could not be separated, it was not possible to identify potential biomarkers for the other two diets.

\section{Identification of individual biomarkers that are different between diets}

In Table 6 , the $24 \mathrm{~h}$ urinary excretion of $\mathrm{N}$, sulphate and creatinine are shown. After adjustment for total $\mathrm{N}$ and creatinine 


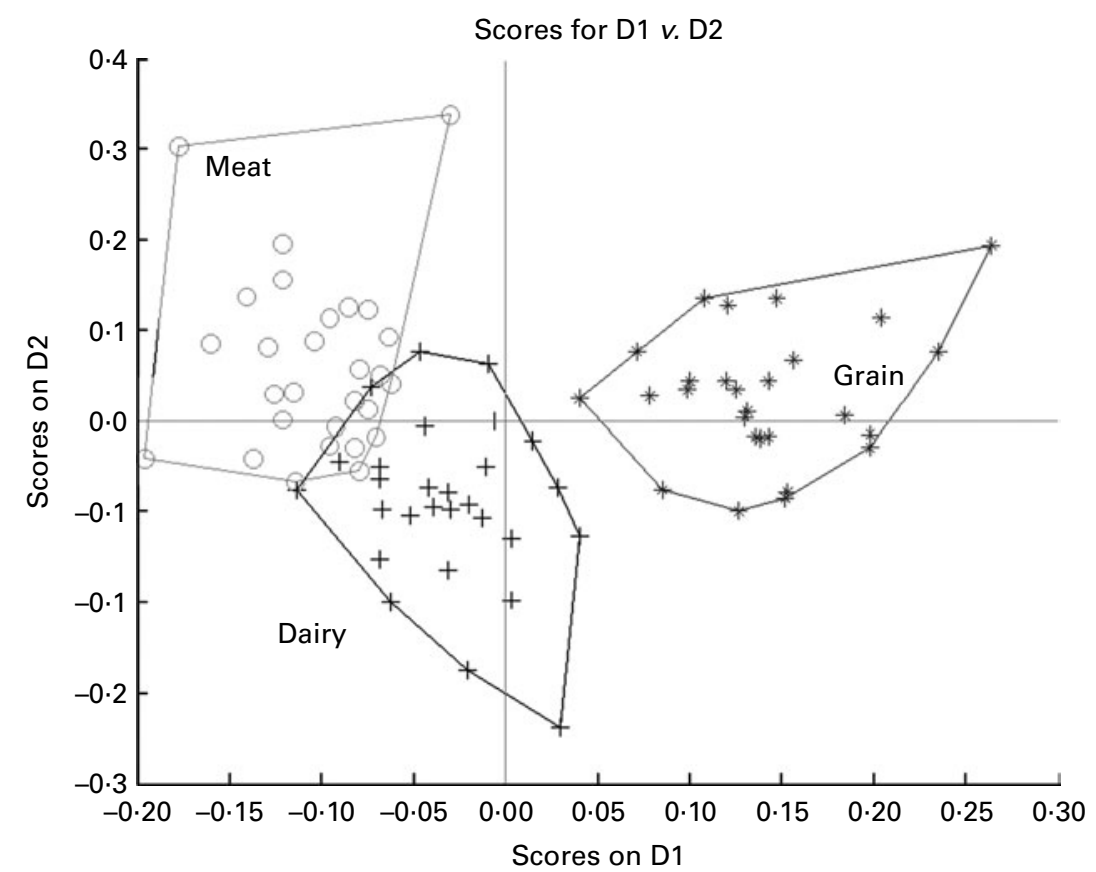

Fig. 3. Principal component discriminant analysis (PCDA) score plot for plasma amino acid profiles of twenty-eight participants in the Biomarker Study. Values of the two discriminant components from PCDA that explained most variation in plasma amino acid profiles. Each dot represents a linear combination of all plasma amino acid levels in one participant during one dietary period. Based on their plasma amino acid profiles, $96 \%$ of participants were correctly classified in the grain protein-based diet, $88 \%$ in the meat protein-based diet and $86 \%$ in the dairy protein-based diet. D1, discriminant 1 ; D2, discriminant 2.

mass and kidney function, the individual $24 \mathrm{~h}$ urinary creatinine excretion is constant in healthy subjects in a steady state. Since the participants of the Biomarker Study were young, apparently healthy people in a steady state and were instructed to keep their physical activity constant during the study, we expect that creatinine excretion remained constant throughout the study, and as such could be used as a marker for urine collection. Although in earlier studies creatinine excretion has been associated with meat intake ${ }^{(7)}$, we did not find an indication of such an association in the present study. We did observe a significantly lower creatinine excretion during the dairy protein-based diet, but urinary creatinine did not explain any variation in dairy protein intake in regression analysis. We therefore expected these differences between diets to be chance findings and considered it justified to adjust all urinary excretion data for creatinine excretion to account for the incompleteness of urine collection.

Meat protein intake was best predicted by a regression model that included urinary carnosine, 1-MH and 3-MH. In literature, urinary carnosine, $1-\mathrm{MH}$ and $3-\mathrm{MH}$ have been proposed as biomarkers for meat protein intake. In an exploratory study in one healthy man, urinary carnosine was increased after ingestion of muscle protein, although the increase was only a small proportion of carnosine ingested ${ }^{(26)}$. In thirtythree non-diabetic obese participants, a linear relationship was found between meat protein intake and 3-MH excretion, with an increment of $1.34 \mu \mathrm{mol} / \mathrm{g}$ of ingested protein ${ }^{(17)}$; and in a Swedish study among five healthy adults, a strong linear relationship was found between meat intake (beef, pork, chicken and plaice) and $3-\mathrm{MH}$ and $1-\mathrm{MH}$ excretion ${ }^{(8)}$. In the present study, a combination of these three AA explained
Table 5. Plasma amino acid levels of twenty-eight participants of the Biomarker Study, relative to run-in: principal component discriminant analysis (PCDA) loadings of discriminant 1 (D1) of Fig. $3^{*}$

\begin{tabular}{lc}
\hline Variable & Loadings D1† \\
\hline Lys & -6.84 \\
Val & -6.60 \\
Thr & -6.32 \\
Abu & -6.26 \\
Cys & -3.97 \\
Leu & -3.21 \\
Hyp & -3.04 \\
Asn & -2.39 \\
Tau & -2.05 \\
Asp & -1.67 \\
Phe & -1.49 \\
His & -1.08 \\
Trp & -0.46 \\
Glu & 0.05 \\
Pea & 0.83 \\
Cit & 0.87 \\
Met & 1.09 \\
Ser & 1.24 \\
lle & 1.45 \\
Gly & 1.46 \\
Ala & 1.48 \\
Gln & 2.55 \\
Tyr & 2.67 \\
Arg & 4.17 \\
Orn & 4.37 \\
Pro & 7.20 \\
\hline Pea, phor &
\end{tabular}

Pea, phosphoethanolamine.

* In PCDA, loadings (or weights) of the discriminant (a linear combination of all amino acids from the profile) reflect the influence of the original variables on differences between diets.

tHigh positive values indicate a high influence of the concerned amino acid on the classification in the grain protein-based diet, whereas high negative values indicate a high influence on classification in one of the two other diets. 
Table 6. Postulated biomarker levels in thirty participants of the Biomarker Study during each diet (Mean values with their standard errors)

\begin{tabular}{|c|c|c|c|c|c|c|c|}
\hline & \multicolumn{2}{|c|}{$\begin{array}{l}\text { Dairy protein- } \\
\text { based diet }\end{array}$} & \multicolumn{2}{|c|}{$\begin{array}{l}\text { Meat protein- } \\
\text { based diet }\end{array}$} & \multicolumn{2}{|c|}{$\begin{array}{l}\text { Grain protein- } \\
\text { based diet }\end{array}$} & \multirow[b]{2}{*}{$P$} \\
\hline & Mean & SE & Mean & SE & Mean & SE & \\
\hline \multicolumn{8}{|l|}{ Urine } \\
\hline Sulphate $(\mathrm{mmol} / 24 \mathrm{~h})^{\star}$ & $35 \cdot 9$ & 1.4 & $31.9 \dagger$ & 1.3 & $35 \cdot 3$ & $1 \cdot 2$ & $<0.01$ \\
\hline Creatinine $(g / 24 h) \ddagger$ & $1.3 \dagger$ & 0.1 & 1.6 & $0 \cdot 1$ & 1.5 & 0.1 & $<0.01$ \\
\hline$\%{ }^{15} \mathrm{~N}$ & 3.685 & 0.002 & 3.684 & 0.002 & 3.683 & 0.002 & 0.06 \\
\hline \multicolumn{8}{|l|}{ Serum } \\
\hline Creatine $(\mathrm{mg} / \mathrm{l})$ & 5.6 & 0.4 & $7 \cdot 2 \dagger$ & 0.4 & $5 \cdot 3$ & 0.4 & $<0.01$ \\
\hline
\end{tabular}

*Adjusted for creatinine excretion and $\mathrm{N}$ excretion.

† Diet different from the other two diets $P<0.01$.

$\ddagger$ Adjusted for $\mathrm{N}$ excretion.

$98 \%$ of variation in meat protein intake, which was more than the variation explained by each of these AA per se. The combination of the three AA may be a useful biomarker for intake of meat protein that warrants validation in controlled studies with different levels of meat protein intake.

It has been shown that after intake of $1-\mathrm{MH}$ and 3-MH from meat, these AA are rapidly excreted in urine and fasting plasma levels are, therefore, very low ${ }^{(7,17,26,27)}$, which is why these plasma levels were not measured in the present study. This may partly explain why, in the plasma AA profile, the grain protein diet showed the best separation from the other diets, in contrast to the urinary profile, where the meat protein diet showed the best separation. A regression model with a combination of plasma concentrations of seven AA (lysine, valine, threonine, $\alpha$-aminobutyric acid, proline, ornithine and arginine) explained $75 \%$ of variation in grain protein intake. Compared with the other two diets, our grain protein diet had a lower content of the essential AA lysine, threonine, valine and methionine, which was reflected in lower plasma levels of the first three AA and in the level of plasma $\alpha$-aminobutyric acid, which is derived primarily from methionine and serine ${ }^{(28)}$. Furthermore, glutamic acid was relatively high in the grain protein diet, which was reflected in a higher excretion of proline, arginine and ornithine for which glutamic acid is a precursor ${ }^{(29)}$. Nevertheless, we should be careful in interpreting these results. Because grains added much bulk to the diet, we replenished the grain proteinbased diet with legumes (chickpeas, lentils; 3.6 en\% legume protein) to reach $14 \mathrm{en} \%$ of plant protein. Additionally, this was the only diet that focused on protein of plant origin, and markers that we identified as potential biomarkers for grain protein may, in reality, reflect plant protein in general. These results need confirmation in other studies with a range in grain protein intake closer to the habitual intake, in which it is not necessary to add protein from other plant sources. Furthermore, plasma AA levels need to be compared between a grain protein-based diet and a diet that contains protein from other plant sources.

A potential marker for which data in human subjects up to date are scarce is the ratio of ${ }^{14} \mathrm{~N}:{ }^{15} \mathrm{~N}$ stable isotopes in urine

Table 7. Regression models of potentially interesting biomarkers from ANCOVA and principal component discriminant analysis (PCDA) with protein types, and explained variation in intake

\begin{tabular}{|c|c|c|c|}
\hline Intake variable (protein \%) & Specimen & Regression model & $\begin{array}{l}\text { \% Explained variation } \\
\text { in intake }\left(R^{2}\right)\end{array}$ \\
\hline \multicolumn{4}{|l|}{$\begin{array}{l}\text { Regression models for AA } \\
\text { with loadings }>4 \text { in PCDA }\end{array}$} \\
\hline Meat protein & Urine & $\begin{array}{l}-16.5+1.0 \times \text { Carnosine }(\mathrm{mg} / 24 \mathrm{~h})+0.2 \times 1 \text {-methylhistidine }(\mathrm{mg} / 24 \mathrm{~h}) \\
\quad+0.5 \times 3 \text {-methylhistidine }(\mathrm{mg} / 24 \mathrm{~h})^{\star}\end{array}$ & 98 \\
\hline Meat protein & Urine & $\begin{array}{l}-10.9+0.9 \times \text { Carnosine }(\mathrm{mg} / 24 \mathrm{~h})+0.2 \times 1 \text {-methylhistidine }(\mathrm{mg} / 24 \mathrm{~h}) \\
\quad+0.5 \times 3 \text {-methylhistidine }(\mathrm{mg} / 24 \mathrm{~h})-2.8 \times \text { proline }(\mathrm{mg} / 24 \mathrm{~h}) \\
\quad-0.3 \times \text { cystine }(\mathrm{mg} / 24 \mathrm{~h}) \dagger\end{array}$ & 98 \\
\hline Grain protein & Plasma & $\begin{array}{l}-42.4+23.3 \times \text { Proline }(\mathrm{mg} / \mathrm{dl})+13.5 \times \text { arginine }(\mathrm{mg} / \mathrm{dl}) \\
\quad+6.8 \times \text { ornithine }(\mathrm{mg} / \mathrm{dll})^{\star}\end{array}$ & 24 \\
\hline Grain protein & Plasma & $\begin{array}{l}99.0+19.9 \times \text { Proline }(\mathrm{mg} / \mathrm{dll})+43.1 \times \text { arginine }(\mathrm{mg} / \mathrm{dl}) \\
\quad+39.9 \times \text { ornithine }(\mathrm{mg} / \mathrm{dll})-32.9 \times \text { lysine }(\mathrm{mg} / \mathrm{dl}) \\
\quad-42.1 \times \alpha \text {-aminobutyric acid }(\mathrm{mg} / \mathrm{dl})-20.9 \\
\quad \times \text { threonine }(\mathrm{mg} / \mathrm{dl})-27.9 \times \text { valine }(\mathrm{mg} / \mathrm{dl}) \dagger\end{array}$ & 75 \\
\hline \multicolumn{4}{|c|}{$\begin{array}{l}\text { Regression models for individual } \\
\text { biomarkers that were significantly } \\
\text { different between diets }\end{array}$} \\
\hline Meat protein & Urine & $-2.4+1.2 \times$ Sulphate $(\mathrm{mg} / 24 \mathrm{~h})$ & 11 \\
\hline Meat protein & Serum & $11.4+42.5 \times$ Creatine $(\mathrm{mg} / \mathrm{dl})$ & 4 \\
\hline Dairy protein & Urine & $43.7-8.2 \times$ Creatinine $(\mathrm{mg} / 24 \mathrm{~h})$ & 0 \\
\hline
\end{tabular}

AA, amino acids.

${ }^{*}$ Regression model containing AA with PCDA loadings $>4$ in the direction of the diet of interest.

$\dagger$ Regression model containing all AA with absolute PCDA loadings $>4$. 
as a biomarker for the proportion of plant and animal proteins in the diet. There is evidence that human hair and bones reflect the proportion of animal protein in the diet ${ }^{(30)}$, and in cattle urine, differences in ${ }^{15} \mathrm{~N}$ isotope levels have been found in response to a maize or a grass diet ${ }^{(31)}$. In line with the hypothesis that the proportion of ${ }^{15} \mathrm{~N}$ increases with higher animal protein intake, we observed, in the present study, a tendency towards a lower percentage of urinary ${ }^{15} \mathrm{~N}$ during the grain protein-based diet compared with the other two diets. However, this difference was too small to be significant. Possibly, a dietary period of 1 week was too short to reach the maximum effect of diet on urinary stable isotope ratio. In cattle, the urinary ${ }^{15} \mathrm{~N}$ required $12 \mathrm{~d}$ to reach the new equilibrium after dietary changes ${ }^{(31)}$. This potential biomarker needs to be investigated in a study with longer dietary periods.

In the present study, among thirty young healthy adults, we identified a combination of three AA in urine as potentially useful biomarkers for the intake of meat protein and a combination of seven AA in plasma as potentially useful biomarkers for the intake of grain protein. We did not find biomarkers for dairy protein intake. Further studies are needed to validate these findings and to investigate whether these biomarkers are also useful within lower ranges of intake, as observed in population-based studies.

\section{Supplementary material}

To view supplementary material for this article, please visit http://dx.doi.org/10.1017/S0007114512005788

\section{Acknowledgements}

We would like to thank all the participants, dietitians, students, kitchen- and laboratory personnel, Dr Carina Rubingh (TNO), Dr Suzan Wopereis (TNO) and other co-workers for their motivation, dedication and valuable contributions to the study. The Biomarker Study was funded by TI Food and Nutrition, public private partnership in food and nutrition research. The mission is to contribute to optimum human nutrition, food safety and sustainable food production and to increase the competiveness of the food industry. Partners are key players in the global food industry, leading research institutes, universities and medical centres. The funders had no role in study design, data collection and analysis, decision to publish or preparation of the manuscript. W. A.-v. d. K., E. J. B., E. S., P. v. V., D. T., S. J. L. B., M. A. B. and J. M. G. designed the research; W. A.-V. d. K., M. B. and E. S. conducted research; W. A.-v. d. K., S. B. and M. B. analysed data; W. A.-v. d. K., E. J. B., M. F. E. and J. M. G. wrote paper; W. A.-v. d. K. has the primary responsibility for the final content of the paper. All authors have read and approved the final manuscript. None of the authors had a conflict of interest.

\section{References}

1. Westerterp-Plantenga MS, Nieuwenhuizen A, Tomé D, et al. (2009) Dietary protein, weight loss, and weight maintenance. Annu Rev Nutr 29, 21-41.
2. Altorf-van der Kuil W, Engberink MF, Brink EJ, et al. (2010) Dietary protein and blood pressure: a systematic review. PLoS One 5, e12102.

3. Gaffney-Stomberg E, Insogna KL, Rodriguez NR, et al. (2009) Increasing dietary protein requirements in elderly people for optimal muscle and bone health. J Am Geriatr Soc 57, 1073-1079.

4. Surdykowski AK, Kenny AM, Insogna KL, et al. (2010) Optimizing bone health in older adults: the importance of dietary protein. Aging Health 6, 345-357.

5. Thompson F \& Subar A (2008) Dietary assessment methodology. In Nutrition in the Prevention and Treatment of Disease, Chapter 1 [AM Coulston and CJ Boushey, editors]. San Diego, CA: Academic Press.

6. Kipnis V, Subar AF, Midthune D, et al. (2003) Structure of dietary measurement error: results of the OPEN biomarker study. Am J Epidemiol 158, 14-21.

7. Dragsted LO (2009) Biomarkers of meat intake and the application of nutrigenomics. Meat Sci 84, 301-307.

8. Sjölin J, Hjort G, Friman G, et al. (1987) Urinary excretion of 1-methylhistidine: a qualitative indicator of exogenous 3-methylhistidine and intake of meats from various sources. Metabolism 36, 1175-1184.

9. Brosnan JT \& Brosnan ME (2006) The sulfurcontaining amino acids: an overview. J Nutr 136, Suppl. 6, 1636S-1640S.

10. Evered DF, Harvey MS, Luck LJ, et al. (1969) The relationship between urinary taurine excretion and the intake of protein-rich foods. Life Sci $\mathbf{8}, 601-605$.

11. Delanghe J, De Slypere JP, De Buyzere M, et al. (1989) Normal reference values for creatine, creatinine, and carnitine are lower in vegetarians. Clin Chem 35, 1802-1803.

12. DeNiro MJ \& Epstein S (1981) Influence of diet on the distribution of nitrogen isotopes in animals. Geochim Cosmochim Acta 45, 341-351.

13. Sponheimer M, Robinson T, Ayliffe L, et al. (2003) Nitrogen isotopes in mammalian herbivores: Hair $\delta^{15} \mathrm{~N}$ values from a controlled feeding study. Int J Osteoarchaeol $\mathbf{1 3}$ 80-87.

14. Halkjær J, Olsen A, Bjerregaard LJ, et al. (2009) Intake of total, animal and plant proteins, and their food sources in 10 countries in the European Prospective Investigation into Cancer and Nutrition. Eur J Clin Nutr 63, S16-S36.

15. Bertram HC, Hoppe C, Petersen BO, et al. (2007) An NMR-based metabolomic investigation on effects of milk and meat protein diets given to 8 -year-old boys. $\mathrm{Br} \mathrm{J}$ Nutr 97, 758-763.

16. Stella C, Beckwith-Hall B, Cloarec O, et al. (2006) Susceptibility of human metabolic phenotypes to dietary modulation. J Proteome Res 5, 2780-2788.

17. Marliss EB, Wei CN \& Dietrich LL (1979) The short-term effects of protein intake on 3-methylhistidine excretion. Am J Clin Nutr 32, 1617-1621.

18. Siebelink E, Geelen A \& De Vries JHM (2011) Self-reported energy intake by FFQ compared with actual energy intake to maintain body weight in 516 adults. Br J Nutr 106, 274-281.

19. AOAC (1997, revised 1999) Official Methods of Analysis of AOAC International, 16th ed. Gaithersburg, MD: AOAC.

20. NEVO (1996) Dutch Food Composition Table (NEVO). The Hague: Voorlichtingsbureau voor de Voeding.

21. Bingham SA (2003) Urine nitrogen as a biomarker for the validation of dietary protein intake. J Nutr 133, Suppl. 3, 921S-924S. 
22. Joliffe T (1986) Principal Component Analysis, 2nd ed. New York: Springer-Verlag.

23. van der Werf MJ, Pieterse B, van Luijk N, et al. (2006) Multivariate analysis of microarray data by principal component discriminant analysis: prioritizing relevant transcripts linked to the degradation of different carbohydrates in Pseudomonas putida S12. Microbiology 152, 257-272.

24. Hoogerbrugge R, Willig SJ \& Kistemaker PG (1983) Discriminant analysis by double stage principal component analysis. Anal Chem 55, 1710-1712.

25. Snijders TAB \& Bosker RJ (1999) Multilevel Analysis: An Introduction to Basic and Advanced Multilevel Modeling. London: Sage.

26. Abe H, Okuma E, Sekine H, et al. (1993) Human urinary excretion of L-histidine-related compounds after ingestion of several meats and fish muscle. Int $I$ Biochem 25 , $1245-1249$.

27. Long CL, Haverberg LN \& Young VR (1975) Metabolism of 3 methylhistidine in man. Metabolism 24, 929-935.

28. Shaw S \& Lieber CS (1983) Plasma amino acids in the alcoholic: nutritional aspects. Alcobol Clin Experimen Res 7, 22-27.

29. Wu G (2009) Amino acids: metabolism, functions, and nutrition. Amino Acids 37, 1-17.

30. O'Connell TC \& Hedges REM (1999) Investigations into the effect of diet on modern human hair isotopic values. $A m \mathrm{~J}$ Phys Anthropol 108, 409-425.

31. Knobbe N, Vogl J, Pritzkow W, et al. (2006) C and N stable isotope variation in urine and milk of cattle depending on the diet. Anal Bioanal Chem 386, 104-108. 